\title{
NEOLITIZAREA TERTTORIULUI ROMÂNIEI ÎN CONTEXT SUD-EST EUROPEAN ŞI ANATOLIAN
}

Nicolae Ursulescu

Consideraţile noastre pornesc de la convingerea că apariţia şi evoluţa neoliticului din sudestul Europei sunt strâns legate (şi în mare măsură dependente) de impulsurile venite, in etape succesive, din Anatolia. Afirmaţia ar putea să pară tranşantă, în condiţile în care problema autonomiei sau dependenței neoliticului sudest european faţă de cel anatolian este încă destul de controversată1. Se gtie că, irjţial, acest punct de vedere, devenit aprnape axiomatic, a dominat concepţiile preistoricienilor ${ }^{2}$, considerându-se că nici n-ar mai fi nevoie să fie demonstrat, cu atât mai puţin apărat. Însă, în timp ce descoperirile neolitice s-au înmulţit spectaculos în sud-estul Europei, în Anatolia cercetările pentru aceeaşl epocă au rămas limitate la un număr restrâns de aşezări. Astfel, ià o suprafaţ̌ aproximativ egală a celor două mari zone (circa $750.000 \mathrm{~km}^{2}$ fiecare), se constată că în Europa de sud-est (Grecia, Bulgaria, Albania, România, statele din fosta Iugoslavie) există peste 300 de aşezări neolitice investigate prin săpături, în lìmp ce în Turcia numărul acestora se ridica doar la vreo $40^{3}$. Acest stadiu al cercetărilor a avut drept urmare că multe dintre fenomenele neolitice recent descoperite în prima zonă nu sji-au mai găsit analogii clare în Anatolia, ceea ce a contribuit la formularea teariilor despre evoluţia complet autonomă a neoliticului sud-est european ${ }^{4}$. Credem că $^{2}$ aceste teorii, apărute prin anii 70, au avut, prin efectul de bumerang, un rol benefic pentru intensificarea cercetărilor de teren în Anatolia și mai ales în zona cheie pentru dovedirea existenţei relaţiilor Anatolia-Balcani, adiç̆ regiunile adiacente Mării Marmara.

Desigur, era eronat din punct de vedere metodologic să se recurgă la comparaţii directe intre regiuni atât de îndepărtate, precum Districtul Lacurilor (Pisidia), cu cunoscuta sa staţune Hacilar şi, pe de altă parte, Thessalia (situată la circa o mie de kilometri), iar de aici elirect în zona dunăreană (cel puţin încă $600 \mathrm{~km}$ în linie dreaptă). Cercetările mai noi au dovedit că, de fapt, cultura de tip Hacilaṛ s-a întins în toată partea sudică a Anatoliei, până la Marea Egee, manifestándu-se printr-un şir de aspecte locale ${ }^{6}$. În acelaşi timp, zona nord-vestică a Anatoliei cunoaşte o serie de alte manifestări ale neoliticului, precum cele descoperite în zona Eskişehir, mai ales la Demircihöyük sau cele de tip Fikirtepe-Pendik", Ilipinar", Asmainler-Aslanapa ${ }^{10}$, fără a se acoperi astfel încă toate petele albe din tabloul geografic ıș cronologic al zonei. În ar:est sens, de o importanţă covârşitoare au fost cercetarile incepute în ultimii ani în zona europeană a Turciei, la Yarimburgaz, Toptepe, Hoca Ceșme ş.a. ${ }^{11}$, deoarece au permis stabilirea unor paralele atât spre nord-vestul Anatoliei, cât şi spre Balcani, acoperied aștfel, într-o oarecaıe măsură, golurile imense de documentare ce se deschideau anterior

\footnotetext{
${ }^{1}$ Demoule 1993

2 pentru un istoric al problemel vezi: Parzinger, Ozdoğan 1995, 6-9; Lazarovid 1996, 21-24

${ }^{3}$ Ozdogan 1989, 202; Parzinger 1993, 195-196

"Renfrew 1972; 1979; Dennel 1983, 155; Todorova 1978

${ }^{5}$ Meliaart 1970

${ }^{6}$ Yakar 1991, 139-179

'Korfmann 1983; Seeher 1987

${ }^{8}$ Bittel 1969/1970; Ozdozan 1983; 1989, 203-204, 207-208

${ }^{9}$ Roodenberg 1993; Thissen 1993

${ }^{10}$ Efe 1993

"Özdoğan 1985; 1993; Parzinger, Özdogan 1995, 929
} 
între centrul Anatoliei şi centrul Balcanilor. Doar insuficienţa datelor de care dispunem în momentul de faţă, atât pentru Anatolia cât şi pentru spaţuł balcanic, determină încă existenţa unei nesigaranţe în trasarea exactă a modalităţilor, căilor şi etapelor prin care s-au transmis aceste influenţe din Anatolia spre Balcani şi Carpaţi, dar s-a făcut deja pasul esenţial în trasarea direcţiei viitoare a cercetării, anume urmărirea din aproape în aproape a etapelor de răspândire a influenţelor dintre cele două zone vecine.

Însă, în atingerea acestui obiectiv există un impediment major, din cauza importantelor modificări suferite de aspectul geomorfologic al celor două zone, de-a lungul celor opt milenii care au trecut de la începutul procesului de neolitizare. Aceste transformări sunt mai accentuate în zonele litorale (prin transgresiunile şi regresiunile maritime), ca şi în văile râurilor (prin depunerile, uneori enorme, de aluviuni). Din aceste cauze, multe din fostele aşezări neolitice se află acum la câțiva metri sub nivelul actual al solului sau chiar sub cel al pânzei freatice actuale; de exemplu, la Demircihöyük doar cincl metri din tell mai sunt vizibili deasupra câmpiei, dar depunerile arheologice continuă cel puţin încă şase metri sub suprafaţa actuală, dintre care circa patru se află chiar sub nivelul pânzei acvatice $^{12}$. Deci, descoperirea unor aşezări neolitice ţine foarte mult de hazard, mai ales în zona Marmara, dar şi pe ţărmurile nordice ale Egeei ${ }^{13}$, o altă cale obligatorie de trecere între Anatolia şi Macedonia-Thessalia ${ }^{14}$. Chiar în cazul telfurilor, s-au păstrat îndeosebi acele situri la care primii ocupanţi au ales locuri deja mai înalte, cu substrat de piatră (pseudo-te/l-uri), ca la Hoca Cesme ${ }^{15}$. Remarcăm şi faptul că descoperirile anatoliene provin aproape în exclusivitate din tell-uri, or se ştie, de exemplu din situaţia sesizaţ̆ în Bulgaria ${ }^{16}$, că locuirea neolitică, în zonele unde există te//uri, înseamnă, în realitate, o alternanţă de aşezari pe tel/uri şi în locurile plane din vecinătate. Numai astfel se poate surprinde o stratigrafie reală și se poate realiza 0 periodizare adevărată a locuirilor neolitice dintr-o zonă. Însă, cel puţin pentru Anatolia, nu dispunem decât de câteva fragmente din ceea ce a însemnat cu adevărat locuirea neolitică în zonă; de aceea, nu avem în prezent la dispoziţie o documentare reală, pentru a putea aprecia, la justa valoare, intensitatea relaţiilor care trebuie să fi existat, în mod normal, între două teritorii vecine. Doar o reconstituire exactă, obţinută prin mari eforturi interdisciplinare, a unor hărţi paleo-geografice a zonelor adiacente celor ttei ımări (Egee, Marmara şi Neagră) va putea să ofere baza pentru o cercetare sistematică, iar nu întâmplătoare, a siturilar neolitice din teritoriile direct implicate în asigurarea legăturii dintre Anatolia şi Balcani.

Cercetarea aşezărilor neolitice din zona Mării Marmara, întreprinsă în ultimii ani, chiar dacă înçă la un nivel restrêns, a arătat totuşi că raporturile culturale dintre Anatolia şi Balcani nu mai pot fi privite atât de simplu ca în trecut, în sensul direcţionării unice a influenţelor dinspre est spre vest. Bogăţia şi varletatea materialelor de tip balcanic, descoperite mai ales în aşezări din zona Marmara, precum cele de la Hoca Ceşme ${ }^{17}$, Yariınburgaz ${ }^{18}$, Toptepe ${ }^{19}$, Demircihöyülk ${ }^{20}$, Orman Fidanliği ${ }^{21}$, dar şi adânc în inima Anatoliei, precum la Gelveri ${ }^{22}$, arată că, cel puţin în unele etape, trebuie să se

\footnotetext{
12 Ozdoğan 1989, 202

13 Némejcová-Pavúkova 1993

${ }^{14}$ Aslanis 1989, 65; Grammenos 1993

15 Ozdogan 1993, 182

${ }^{16}$ Georgiev, 1966, 398; Vajsova 1966, 8

${ }^{17}$ Özdoğan 1993, 182-186

${ }^{10}$ Idem 1985; 1989, 204, 209-214; Parzinger, Ǒzdoğan 1995

19 Parzinger, Ózđoğan 1995, 16

${ }^{20}$ Korfmann, 1983; Seeher 1987

${ }^{21}$ Efe 1990

7 Esin 1993, 47-56
} 
vorbească de o interacţiune $e^{23}$. Deci, măcar pentru bazinul Mării Marmara, credem că ar fi putut exista o alternanţă între transmiterea influentelor anatoliene spre Balcaai şi fenomenele de interacţune culturală, cele din urmă dobândind tot mai mult teren o dată cu trecerea spre chalcolithic. În acest sens, Europa de sud-est nu mai poate fi privită doar ca un simplu receptacul, care a primit, la anumiłe intervale, noi valuri de populaţil și de influenţe onatoliene. Chiar dacă aceste influente s-au transmis (mai ales în etapele initgiale ale neoliticului) prin aporturi destul de importante de populatie anatoliană, demonstrate şi de datele antropologice ${ }^{24}$, totuşi acestea au dobândit, în scurtă vneme, forme culturale noi, atât prin adaptarea celor veniţi la noile condiţii ecologice, cât şi prin participarea efectivă a populaţiilor epipaleolitice locale (prin asimilare sau prin aculturaţie) la procese de sinteză culturalą25. De aceea, Intensitatea relaţiilor Balcanilor cu Anatolia trebuie privită diferenţiat, în sensul că regiuhile din estul Balcanilor au fost primul beneficiar al acestor influenţe, iar pe măsură ce ne îndepartăm spre vest și spre nord scade prezenţa elementelor pur-anatoliene, acestea fiind înlocuite $\mathrm{cu}$ altele, deja trecute prin filtrul unor sinteze locale. Deci, deşi există influenţe de tip anatolian în tot acest spaţiu, ele apar totuşi cu diferenţe, uneori notabile, de la o zonă la alta.

S-a subliniat adesea că dezvoltarea neoliticului anatolian are mai multe elemente comune cu Europa de sudest decât cu Asia Anterioară ${ }^{26}$, motiv pentru care a şi fost formulat conceptul de "complex cultural balcarıo-anatolian"27, a cărui evoluţie poate fi urmărită de-a lungul mai multor letape ale neoliticului şi chalcolithicului. Totuşi, istoria acestui mare complex cultural (a cărui influenţă se poate sesiza pe o suprafaţă unaşă) nu poate fi bine înţeleasă, în sensurile ei majore, atâta vreme cât, dincolo de lacunele de documentare, există impedimente serioase şi în privinţa terminologiei total diferite, aplicatð perioadelor neoliticului şi chalcolithicului din Anatolia şi din diferitele zone ale Europei de sud-est ${ }^{28}$. Având în vedere în primul rând ceea ce uneşe evoluţia din cele două mari regluni, considerăm că s-ar impune o unificare a periodizărilor, în sensul adoptării schemei anatoliene, regiunea care dă totuşi tonul acestui ritm cvasi-similar de dezvoltare. Nu credem că e normal să se considere că Europa sud-estică ar rămêne mereu, din punct de vedere al evoluţiei, în urma Anatoliei ${ }^{29}$. Chiar existenţa unor fenomene de periferizare în unele regiuni sud-est europene e similară cu situaţia întâlnită în anumite zone ale Anatoliei, mai ales nordice, fără ca aceasta să afecteze, însă, periodizarea unitară a neoliticului şi chalcolithleului anatolian. Normıl ar fi, deci, ca periodizările să ţină seama de nivelul culminant atins de o vastă regiune la un moment dat, iar nu de diferitele aspecte periferice; acestea preiau oricum câte ceva din cultura zonelor mai avansate, existând deci o contemporaneitate între cele două categorii de teritorii. $O$ uniformizare a perlodızărilor neollticului şi chalcolithicului din Anatolia şi Europa de sud-est ar putea să contribuie, în mare măsură, la o mai bună inţelegere a liniilor generale de evoluţe din cele două zone şi, deci, la urmărirea în mai bune condiţi a modultii în care s-an transmis şi au fost adoptate influentele caḷurale, într-un anumit moment.

Considerăm că pentru stabilirea unor eventuale paralele şi influente între Anatolia şi sudestul Europei esenţiali sunt factorii ceramică, plastică şi rit funerar, deoarece sunt cel mai puternic legaţi de o annmită tradiţie, mai ales spinituală, de o anumită forma mentis ${ }^{30}$. Însă, adeseori se pune

\footnotetext{
${ }^{23}$ Yakar 1997

24 Necrasov, Cristescu 1973; Mikic 1990

${ }_{25}$ Benac 1978; Garašanin 1978; Jovanovic 1965; 196a; Comşa 1978)

26 Parzinger 1993, 195)

${ }^{27}$ Mellaart 1960; 1975; Garaక̌anin 1961; 1971)

29 Özdoğan 1989, 201)

29 Séfériadès 1993, 9)

${ }^{30}$ Ursulescu 1993, 335
} 
un deosebit accent (într-o manieră exagerată, după părerea noastră) pe similitudinea sau schimbarea tipurilor şi a tehnicilor de construcție, dar in istorie se cunosc numeroase cazuri în care aceeaşi populaţie, în cadrul aceleiaşi culturi, utilizează tipuri diferite de locuinţe, în funcţie de specificul zonei în care se aşează, de materielele existente, ca și de mărimea și priceperea grupului care participă la construcţie. În acest sens, un caz bine cunoscut este cel al purtătorilor culturii ceranicii liniare, care în zonele Europei centrale construiau mai ales tipicele locuinte /ungi ${ }^{31}$, în timp ce dupa migrarea lor în zonele răsăritene (Moldova, vestul Ucrainei) au ridicat doar locuințe de mlci dimensiuni, chiar adâncite $^{32}$. Dealtfel, oamenii au avut în toate timpurile o mare putere de adaptibilitate în ceea ce priveste condiţile de locuit şi de aceea considerăm că factorul locuintă nu este atât de relevant pentru aprecierea existenţei sau inexistenţei legăturilor dintre Anatolia și sud-estul Europei.

Marile orizonturi culturale care au contribuit treptat la neolitizarea sud-estului Europei au cunoscut o răspândire gradulală şi o evoluţie de la forme iniţiale destul de unitare spre forrne clin ce în ce mai diversificate. Fenomenul este în mare măsură similar cu cel din Anatolia, care a cunoscut şi ea o răspândire treptată a formelor de viaţ̆ neolitică dinspre est şi sud spre vest şi nord ${ }^{33}$. Acest ritm şi această direcţie a evoluţiei, în oarecare măsură similare în cele două mari zone, pot fi de asemenea invocate ca argumente suplimentare pentru existenţa unor mişcări culturale şi etnice, care s-au desfăşurat predominant dinspre Anatolia spre sudestul Europei. Deplasarea grupurilor de populaţii neolitice s-a produs, de regulă, din aproape în aproape, dar puteau să existe şi cazuri de stabilire la mare distanţă, fără staţiuni intermediare. În primul caz, prin descoperirea unor aşezări cu aspect înrudit se poate jalona pe hartă drumul sau căile de răspândire a acestor comunităti. Însă, în cea de a doua situaţ̧e intervine mai ales hazarctul descoperirilor şi, evident, legăturile sunt mult mai dificil de reconstituit. Aceasta pare să fie situaţa maai ales în cazul primelor comunităţi neolitice din spaţiul central- şi nord-balcanic, adică a celor considerate ca aparţinând fie unui neolitic aceramic, fie primelor orizonturi cu ceramică (monocrom și Proto-Starčevo sau Proto-SeskJo).

Un prim asemenea orizont îl reprezintă neoliticul aceramic, atestat în sudul şi sudestut Anatoliei (Çayönü, Nevali Çori, Cafer Höyük, Aşikli, Çatal Höyük etc), care îşi are rădăcinile în PrePottery Neolithic A din Levant şi nordul Mesopotamiei ${ }^{34}$. De aici s-a produs o extindere şi spre zona centrală a Anatoliei, la Hacilar ${ }^{35}$; cu toate acestea raporturile dintre cele două zone anatoliene ale neoliticului aceramic nu sunt tocmai clare ${ }^{36}$. Cu toată lacuna de documentare existentă în vestul Anatoliei, ca şi în regiunile răsăritene ale Balcanilor, un asemenea orizont neolitic aceramic a fost propus şi pentru unele zone batcanice, ln primul rând în Thessalia ${ }^{37}$. E vorba de complexe găsite sub cele mai vechi depuneri cu ceramică, considerate, din punct de vedere stratigrafic, preceramice. Cele câteva fragmente ceramice descoperite în aceste "nivele aceramice" au fost considerate probabil ca intrusive $^{3 \theta}$. În acelaşi context cultural au fost luate în consideraţie şi complexe care par să fie mai

\footnotetext{
31 Soudský 1969; Pavúk 1970; Meier-Arendt 1989

Passek, Cemys 1963; Ursulescu 1991, 208-211

${ }^{3}$ Cauvin 1988, 77-79; Yakar 1997, 63-64

${ }^{34}$ Cauvin 1988, 77; Yakar 1997, 63, n.7

35 Mellaart 1970; 1975

36 Yakar 1997, 63

37 Miloj ̌ić 1960; Berciu 1958; Lazarovici 1996, 23-24

Lichardus ş.a. 1985, 230-231; Perles 1987; Hachmann 1986, 14
} 
degrabă rezultatul unor procese de aculturație, din partea unor comunităţi deja neolitice, cum ar fi cele descoperite la Franchti, în Peloponez ${ }^{39}$, la Crvena Stijena IV, în Muntenegru ${ }^{40}$, în cultura Lepenskj Vir-Schela Cladovei, din regiunea Porţilor de Fier ${ }^{41}$ sau la Soroca, pe Nistru ${ }^{42}$. Însă, în toate cazurile menţionate nu există certitudinea că, în afară de un început de viaţă sedentară, s-ar fi practicat şi o economie de tip neolitic, descoperită prin eforturi proprii, sau fuseseră doar împrumutate unele manifestări ale noului mod de viaţa ${ }^{43}$. Chiar şi în Anatolia, în aşezări considerate ca aparţinând neoliticului aceramic, nu există pretutindeni urme clare de economie neolitică, cu excepţa vieţii sedentare, ca de exemplu la Suberde ${ }^{44}$.

Oricum, aceste prime încercări de trecere la viaţa neolitică s-au desfăşurat și ele în momente diferite, mai vechi în sud şi mai recente spre nord ${ }^{45}$. Astfel, în Anatolia, ceva mai timpurii sunt aşezarrile neolitice aceramice din sud-est, faţă de cele din sudul podişului, toate încadrându-se însă în prima jumătate a mileniului VII B.C. ${ }^{46}$. De asemenea, datele din straturile considerate ca aparţinând neoliticului aceramic din Thessalia (Argissa, Sesklo etc.), se încadrează într-un interval de timp care începe cu al doilea sfert al mileniului VII B.C. ${ }^{47}$, fiind vorba, deci, de un oarecare decalaj față de Anatolia. Datele aceluiaşi orizont din peștera Franchti sunt și mai târzii ${ }^{48}$, arătând că în Peloponez era vorba, probabil, doar de un proces de aculturaţie a unor comunităţi epipnleolitice, contemporăne cu comunităţi deja neolitice din Thessalia. La sfârşitul mileniılui al VII-lea B.C. și în prima jumătate a celui următor se plasează şi decoperirile de tip Lepenski Vir-Schela Cladovei ${ }^{49}$ sau cele de la Soroca ${ }^{50}$, considerate de unii cercetători ca reptezentând o formă de neolitic preceramic, în timp ce alţii le consiferă doar un epipaleolitic (sau mezolitic), perfect adaptat condiţilor dintr-o microzonă favorabilă sedentarizării ${ }^{51}$.

Asemenea comunităţi, considerate de unii cercetori ca aparținând neoliticului preceramic, par să nu fie ăìins însă, nirăieri în Balcani, maturizarea tuturor aspecilelor vieţii neolitice, deoarece aceste comunităţi epipaleolitice (mezolitice), în curs de neolitizare, au fost destul de curând absorbite de noi valuri de populaţie neolitič̆, aflate în plin proces de expansiune teritorială. Se pare că un fenomen similar s-a produs şi în unele situri din Anatolia, precum la Karain, unde există o suprapudere de aşezări mezolitice, neolitice aceramice şi ceramice timpuriji ${ }^{52}$ sau la Beldibi şi Belbaşi, cu aşezări mezolitice şi neolitice timpurii ${ }^{33}$. Deci, după părerea noastră, suprapunerea unei așezări neolitice timparii peste alta aparţinând unưi eventual neđlitic aceramic nu înseamnă neapărat că una derivă din alta, ci că, mai curând, locul respectiv a fost considerat favorabil de noii veniţi, care i-au asimilat, nimicit sau alungat pe vechii locuitori. Colonizarea neolitică trebuie să se fi inscris, desigur, în parametri asemănători altor tipuri de colonizare, cunoscute pe parcursul evoluţiei istorice, cu aceleaşi consecinţe în raporturile dintre noii veniţ şi populaţa anterioară.

\footnotetext{
Jacobsen 1973; Tellenbach 1983, 28

Benac 1957; Tellenbach 1983, 29-30

${ }^{11}$ Srejovic 1971; Boroneant 1973; Lazarovid 1983; 9-16; Tellenbach 1983, 30-32, 36

Markevici 1974; Ursulescu, Dergacev 1991, 161-162

${ }^{40}$ Dumitrescu 1971

"Ehrich 1992, I, 209

${ }^{45}$ Parzinger 1993, 253-254; Yakar 1997, 63-65

${ }^{*}$ Ehrich 1992, 171, 174-175

${ }^{47}$ ibidem, 204, 209

- pe la 6300-6000 B.C.: ibidem, 209

- Boroneant 1973; Dolukhanov, Timofeev 1972, 49; Tas|C 1990

50 Markevid 1974, 128

${ }^{51}$ Dumitrescu, Bolomey, Mogosanu 1983, 25-29, 52-54; Dumltrescu, Vulpe 1988, 16; Benac, Marijanoví̌ 1993,127

$\Omega$ Parzinger 1993, 242

5] Ibidem, Ehrich 1992, I, 208
} 
Dacă pentru neoliticul aceramic, relaţille Balcanilor cu Anatolia sunt în prezent mai mult presupuse decât clar atestate, in schimb aşa-rıumitul orizont cu ceramică monocromă a început să fie tot mai clar delimitat, chia dacă încă nu în prea multe locuri ${ }^{\text {S4 }}$. Cea mai reprezentativă aşezare este considerată, în momentul de faţă, cea de la Achilleion, din Thessalia ${ }^{55}$. Din păcate, nu s-a ajuns încă la o definire clară şi la o accepţune unitară în privinţa noţiunii de orizont cu ceramică mononcromă. În afară de ceramica monocromă propriu-zisă (de foarte bună calitate, perfect arsă, cu pereţi subţiri), unii cercetători inclưd în această categorie şi ceramica grosieră nepictată, iar alţi vorbesc de orizont monocrom chiar şi atunci când apare, alături de specia nepictată, şi cea pictată, dar în proporţii reduse. Este evident că această situaţie conduce la confuzii şi la estomparea identităţi culturale şi a valorii cronologice a acestui orizont, implicit la imposibilitatea de a stabili exact realţia corectă cu complexele similare din Anatolia ${ }^{56}$.

Cercetările recente de la Krajnici, în valea superioară a Strumei (Bulgaria), au identificat un orizont monocrom, bine separat printr-un strat de aluviuni, de stratul cu ceramică pictată, de tip Gălăbnik $^{57}$, dovedindu-se că formele ceramice monocrome prezintă deosebiri destul de importante faţa de cele din nivelul cu picturăas . Astfel s-a dovedit că nivelele cu ceramică monocromă (acolo unde există cu adevărat) reprezintă un orizont cultural şi cronologic aparte, nu doar o parte componentă a orizontului urmätor, Proto-Sesklo sau Proto-Starčevo. Desigur, grupele cu ceramică pictată cu alb se formează parţial pe baza orizontului precedent și, de aceea, au inclus o cantitate apreciabilă de ceramică monocromă, dar aceasta a fost prelucrată deja după alte tipare. Ar fi deci de dorit ca termenul de monocrom să se utilizeze doar pentru ceramica primului orizont neolitic (Frühkeramik), evitând-se astfel confuzii cronologice şi culturale.

In momentul de faţă, orizonturi clar monocrome par a fi documentate, în afară de bazinul superior at Strumei (Krajnici), in Thessalia, la Achilleion, Argissa, Sesklo, Otzakj, Soufli ş.a. ${ }^{59}$ şi în partea de nord a Bulgariei, în bazinul Lomului, la Koprivec, Červen, Orlovets I, Poljanitsa ${ }^{60}$ şi în bazinul Iantrei, la Bjala ${ }^{61}$. Un alt grup de aşezări, din zona nordică a Serbiei ${ }^{62}$, atribuit de unii cercetători orizontului monocrom ${ }^{63}$, pere să aparţnă mai degrabł̆ orizontului Proto-Starčevo, caracterizat prin ceramică pictată $\mathrm{Cu} a \mathbf{l b}^{64}$. Pentru aria nord-dunăreană descoperirile de până acum nu au dovedit stratigrafic existenţa unui asemenea orizont, anterior celui cu ceramică pictală cu alb, deşi unii cercetători î postulează în mod ipotetic ${ }^{65}$, doar pe baze tipologice, dorindu-se să se păstreze astfel acel presupus Starčevo I monocrom ${ }^{66}$.

Următorul orizont, cel cu ceramică pictată cu alb, corespunzând nivelurilor Hacilar VI-V din Anatolia ${ }^{67}$, acopară cea mai mare parte a Balcanilor, atlându-se la baza viitoarelor mari complexe

\footnotetext{
54 Parzinger 1993, 253-254; o sinteza la Lazarovid 1996, $24-25$

55 Gimbutas 1974

56 Efe 1990, 91, 100

57 Cochadžiev, Bakamska 1990

$\$$ Pavúk 1996, 39

59 Lazarovici 1996, 24, cu bibliografie

${ }^{60}$ Popov, Vajsov 1994; Todorova 1995, 83-84

61 Todorova 1995, 83-84

62 Donja Branjevina III, Lepenskj Vir III a, Padina B, Divostin: Pavúk 1993, 235

${ }^{63}$ Srejović 1971, 14; 1973, 259-261; Dimitrijević 1974, 95-96; 1979, 242-243; Garašanin 1979, 118-120

64 Lazarovidi 1996, 24-25

65 ibidem, 25; Lazarovici, Maxim 1995: etapa Startevo-Criş la

${ }^{66}$ propus, de asemenea ipotetic, la începutul anilor '50: Milojdić 1949, 70-71; 1950, 108-118; Lazarovid 1979, 17-18; Pavúk 1993, 231

${ }^{67}$ (Parzinger 1993, 254-255, Beilagen 3-5
} 
neolitice SeskJo, Karanovo, Starčevo ${ }^{68}$. Conform modelului succesiunii Protosesklo-Sesklo, s-a propus şi pentru viitoarea arie a culturii Starčevo, denumirea de Protestarčevo ${ }^{69}$, în care au fost incluse numeroasele grupe locale, descoperite în ultimele decenii pe teritoriul Bulgariei ${ }^{70}$, Macedoniei răsăritene ${ }^{71}$, Pelagoniei ${ }^{72}$, Albaniei ${ }^{73}$, Serbiei ${ }^{74}$ şi României ${ }^{75}$. Aceste grupe vor sta la baza evoluţiei unar variante ale culturii Starčevo-Criş ${ }^{76}$, precum în cazul aspectului Cârcea-Gradešnica, din zona Olteniei şi a regiunii învecinate din nord-vestul Bulgariei. Această recentă definiție, bine formulată de Juraj Pavúk (1993;1996), a lărgit mult aria de cuprindere a orizontului Protostarčevo, faţă de modul în care fusese definit acesta de Dragoslav Srejović (1971), pe baza descoperirilor sale de la Lepenski Vir, cuprinzând doar teritoriul Serbiei şi al României, cu aceeaşi accepţie ca şi denumirile de grupa Donja Branjevina ${ }^{7}$ sau grupa Gura Baciulu'? ${ }^{7}$. Rămâne doar dificil de înteles de ce J. Pavúk a desemnat acest orizont drept cultura Protostarčevo, din moment ce, de fapt, este doar prima fazł a altei culturi (Starčevo), de la care a împrumutat și numele. Probabil că singura justificare ar fi dorinţa de a stabili o paralelă cât mai evidentă cu evoluţia din Thessalia, deşi şi acolo denumirile utilizate de multă vreme în literaturo arheologică prezintă, după părerna noastră, o eroare de logică, deoarece nà credem că e normal ca după "primul Sesklo" (Protosesklo) să urmeze o cultură "anterioară lui Sesklo" (Presesklo)!

Merită mentionat şi faptul că acest orizont cu ceramică pictată cu alb a fost recent semnalat şi în Turcia europleană, în nivelul inferior de la Hoca Cesme ${ }^{79}$, ceea ee poate constitui o verigă de legătură a Anatoliei atât cu grupul Protosesklo, cât şi grupul Karanovo I, dar şi cu aşezarea recent descoperită la Kovacevo (în bazinul inferior al Strumei, lângă granița greco-bulgară), care rămâne încă un aspect cultural izolat $t^{\text {OO }}$.

Trecerea spre cultura Starčevo propriu-zisă se face printr-un orizont în care pictura albă se amestecă cu cea roşie, aşa cum au arătat descoperirile din Bulgaria, de la Gălăbnik ${ }^{\text {11 }}$ şi Pernik ${ }^{82}$, din Serbia, de la Grivac ${ }^{83}$ sau din România, de la Cârcea ${ }^{84}$. Începuturile culturii Starčevo, prin pictura liniară roşie, își găsesc bune analogii în mediul anatolian al culturii Hacilar - fazele V-II ${ }^{85}$, ca şi în mediul Sesklo din Thessalia ${ }^{86}$.

În perioada recentă a marilor complexe neolitice timpurii din Balcani (Sesklo, Karanovo II, Starčevo III-IV) se constată schimbări semnificative, care au stat la baza naşterii unui nou mare complex cultural. Aceste schimbări nu au afectat doar Balcanii, ci şi vaste zone ale Europei Centrale. Aceleaşi modificări de esenţă sunt resimb̧te și în întreaga Anatolie, spre mijlocul mileniului VI B.C., în

\footnotetext{
${ }^{6}$ Pavík 1993

9 ibidem

${ }^{7}$ Gălăbnik, Kremikovci, Slatna, Gradežnica: Pavúk, Cochadžiev 1994; Ravúk, Bakamska 1989; Georgiev 1973; 1975; 1981; Nikolov V. 1984; 1989; 1995; Nikolov V., Grigorova, Sirakova 1992; Nikolov B. 1974; Todorova 1995, 83-84

${ }_{1}$ Anzabegovo I - Vršnik I: Gimbutas 1972; 1976; Garasanin M. 1979, 92-94; Garał̌anin D. 1989; Koroł̌ek 1973; Pavúk 1993; Zdravkovskj 1990; Garašanin D. și M. 1961

$n$ veluska-Porodin: Grtic 1960; SImoska, Sanev 1975; Pavúk 1993, 233-234

3 Podgorje: Prendi 1990

${ }^{4}$ Donja Branjevina: Karmanski 1968; 1975; 1979; 1988; 1991

${ }^{\pi}$ Gura Baciulul, Cárcea, Ocna Sibiului: Vassa 1972; Lazarovici 1984; 1995; Lazarovici, Maxim 1995; Nica 1976; 1977; 1991; 1995; Paul 1989, 1995

* Pavúk 1993, 235-236

$n$ propusă de Sergej Karmanskj 1968

70 propusă de Milutin şi Draga Garał̌anin: 1979; 1989

Tozdoğan 1993, 185-186; Parzinger, Ózdogan 1995, 14-15

o Perniceva 1990; 1995, 100-106

11 Pavík, Cochadžiev 1984; Pavúk, Bakamska 1989

Cochadžiev M. 1984

Bo Bogdanovic 1987

Nica 1976; Bakamska, Pavúk 1995, 36-39

05 Mellaart 1970, 92, fig.59, 62

Do Parzinger 1993, 256; orizontul 3a-b
} 
complexe precum Çatal Höyük-Vest II, Can Hasan II, Hacilar I, Ilipinar V, Yarimburgaz 0 şi altele, încadrate de H.Parzinger în orizonturile sale 3c-4 (1993, 257-258) sau de J.Lichardus în perioada 7 (1985, 188-192). Cauza acestor modificări, petrecute în momentul apariţiei chalcolithicului anatolianobalcanic, ar putea fi extinderea noii culturi Halaf (formată în nordul Mesopotamiei) şi a influenţelor sale, resimb̧ite pe o arie extrem de vastă. Noua modă culturală nu se manifestă în Balcani doar prin apariţia formelor de vase cu bitronconism accentuat, puternic lustruite şi decorate cu caneluri, ci şi printr-o frumoasă ceramică cu pictură tricromă, care înlocuiește, în multe regiuni, pictura roşie. Nu este exclus ca acest nou tip de pictură, atestat printre altele şi în aria Starčevo-Cârcea, să se fi inspirat din frumoasa pictură policromă halafiană ${ }^{\theta 7}$. Se formează iarăşi, în toată Europa sud-estică, un mare număr de noi grupe locale (Dimini, Paradimi, Karanovo III, Anzabegovo IV etc.) ${ }^{80}$, dar toate ar putea fi încadrate în orizontul sau fenomenul Vinča timpuriu (faza A), denumit astfel după grupa cea ınai reprezentativă ${ }^{99}$. În aria culturii Starčevo, primele comunităţi vinčiene (din subfaza $A_{1}$ ) au apărut la nivelul fazei Starčevo III $B^{90}$. Această situaţie a determinat, printre altele, 0 exitindere rapidă a comunităţilor Starčevo-Criş (care încorporaseră deja unele elemente de tip vinčian) spre zone periferice învecinate, care nu cunoscuseră până atunci modul de viaţă neolitic: Slavonia ${ }^{91}$, Transdanubia ${ }^{92}$, Moldova ${ }^{93}$ etc., iar la periferia nordică şi vestică aceste comunităţi starčeviene târzii au contribuit, înı mod decisiv, la naşterea marelui complex central-european al ceramicii liniarbandate ${ }^{94}$.

Tocmai acest puternic impuls anatolian a stat la baza încheierii procesului de neolitizare în aproape întreaga Europă de sud-est, ca şi în cea mai mare parte a zonei temperate a continentului, deci şi pe actualul teritoriu al României.

Asemănările dintre Europa de sudest şi Anatolia au devenit acum atât de evidente încât conceptul de complex cultural al chalcolithicului balcano-anatolian a fost propus iniţial tocriai pentru această perioadă. O dată cu aceasta, Balcanii au intrat într-o nouă etapă istorică, cea a chalcolithicului, marcată printr-un caracter extrem de dinamic al culturilor sale, manifestat, între altele, prin întreţinerea unor puternice raporturi de interacţune cu culturile anatoliene contemporane ${ }^{95}$.

\footnotetext{
"Dabbagh 1966

- Lazarovici 1977; Chapman 1981, 1-5, 33-39

${ }^{89}$ Ozdogan 1993, 174-175

${ }^{90}$ Luca 1991

91 Dimitrijević 1969; Minichreiter 1992

92 Kalicz 1990

${ }^{93}$ Ursulescu 1984; Ursulescu, Dergacev 1991

94 Quitta 1960; 1962; Soudský, Pavl0 1966; Lichardus 1972; Pavúk 1980; 1994; 1996, 42-43; Lazarovid $1984 a ; 1985$

95 Srejovic 1963; Popovitch 1965; Quitta 1971; Chapman 1981; Efe 1990; Ozdołan 1993; Parzinger, Ozdogan $1995 ;$ Pardnger 1993
} 


\section{ABREVIERI}

Arch.Iug

AM Nap

AM Por

BAM

BAR

Ber RGK

Dacia, NS

ERAUL

NNU

PamArch

$\operatorname{SCIV}(A)$

SlovArch

SovArch

VAH
Archaeologia Iugoslavica, Beograd.

Acta Musei Napocensis, Cluj-Napoca.

Acta Musei Porolissensis, Zalău.

A Béri Balogh Adám Múzeum Evkönyve, Szekszárd.

British Archaeological Reports, Oxford.

Bericht der Römisch-Germanischen Kommission, Mainz am Rhein.

Dacia. Revue d'archéologie et dhistoire ancienne. Nouvelle Série, Bucharest.

Études et recherches archéologiques de /Université de Liège.

Nachrichten aus Niedersachsens Urgeschichte, Hildesheim.

Památky archeologike, Praha.

Studii şi cercetari de istorie veche (și arheologie), Bucuresti.

Slovensks Archeologia, Nitra.

Sovetskaja Archeologija, Moskva.

Varia Archaeologica Hungarica, Budapest.

\section{BIBLIOGRAFIE}

\section{Aslanis Ioannis}

1989 Das Neolithikum und Chalkolithikum im nordgriechischen Raum,in Tell Karanovo und Balkan-Neolithikum,Salzburg, p. 65-81.

\section{Bakamska Aneta, Pavúk Juraj}

1995 Die rotbemalte Keramik und der Anfang der Startevo-Kultur, AMNap, 32, 1, p. $29-45$.

\section{Benac Alojz}

1957 Črvena Stijena - 1955 (I-IV Stratum), Glasnik-Sarajevo, 12, p. 19-50.

1978 Les thèses fondamentales sur lorigine du nèlithique dans les Balkans et les regions avoisinantes, Godišnjak, XVI, Sarajevo, p.91-100.

\section{Benac A., MarijanoviX Bronislav,}

1993 Les Balkans du Nord-Ouest in Atlas du Néolithique européen, I (éd. J. Kozlowski), ERAUL, 45, Liège, p.127-150.

\section{Berciu Dumitru}

1958 Neolithic preceramic in Balcani, SCIV, 9, 1, p.91-100. 


\section{Bittel Kurt}

1969/1970 Bemerkungen über die prähistorische Ansiedlung auf dem Fikirtepe bei Kadiköy, Istanbuler Mitteilungen, 19/20, p. 1-19.

\section{Bogdanović Milenko}

1987 Neolitičeskije poselenija v Divostine i protostarčevskaja kultura, SovArch, 2, p.5-17.

\section{Boroneant Vasile}

1973 Recherches archéologiques sur la culture Schela Cladovei de la zone des Portes de Fer, Dacia, NS, XVII, p. 5-39.

\section{Cauvin Jacques}

1988 La néolithisation de la Turqive du sud - est dans son contexte proche-oriental, Anatolica, XVI, p. 69-80.

\section{Chapman John}

1981 The Vinča culture of South-Est Europe, BAR-Intern.Series, 117 (I-II).

\section{Cochadžiev $M$.}

1984 Die Ausgrabungen der neolithiscen Siedlung in Pernik, NNU, 52, p. 29-68.

\section{Cochadžiev Stefan, Bakamska Aneta}

1990 Etude du site néolithique ancien de Krainitsi dans le département de Kustendil, Studia Praehistorica, 10 , p.51-76.

\section{Comşa Eugen}

1978 Quelques données sur le processus de la néolithisation dans la Roumanie, Acta Archaeologica Carphatica, XVII, p. 69-74.

\section{Dabbagh Takkey}

1966 Halaf Pottery, Sumer, XXII, 1, p.23-43.

\section{Demoule Jean-Paul}

1993 Anatolie et Balkans: la logique évolutive du Néolithique égéen, Anatolica, XIX, p.1-17.

Dennell R.

1983 European Economic Prehistory, Academic Press, London.

\section{Dimitrijevic Stojan}

1969 Die Starčevo-Kultur im slawonisch-symischen Raum und das Problem des Übergangs vom älteren zum mittleren Neolithikum im serbischen und kraatischen Donaugebiet, vukovar.

1974 Das Problem der Gliederung der Starčevo-Kultur mit besonderer Rücksicht auf den Beitrag der südpannonischen Fundstellen zur Lösung dieses Problems, Materijali, $\mathrm{X}$, Boegrad, p. 50-121.

1979 Sijeverna zona, in Praistorija Jugoshovenskich zemalja, Sarajevo, p.229-262.

\section{Dolukhanov P.M., Timofeev V.I.}

1972 Absoljutnaja khronologhija neolita Evrazij (po dannym radio- uglerodnogo metoda), in Problemy absoljutnogo datirovanija v archeologhii, Moskva, p.28-75. 
Dumitrescu Vladimir

1971 Le début du Néolithique au nord du Danube en Roumanie, in Actes du VIr Congrès Int. des Sciences Pré- et Protohistoriques, I, Beograd, p.85-96.

\section{Dumitrescu Vl., Bolomey Alexandra, Mogosanu Florea}

1982 Esquisse d'une préhistoire de la Roumanie, Bucarest.

\section{Dumitrescu VI., Vulpe Alexandru}

1988 Dacia înainte de Dromihete, Bucuresti.

\section{Efe Turan}

1990 An Inland Anatolian Site with Pre-Vinça Elements: Orman Fidanliği, Eskişehir. A Reexamination of Balkan-Anatolian Connections in the Fifth Millenium BC, Germania, 68, 1, p.67-113.

1993 Chalcolithic pottery from the mounds Aslanapa and Kinik, Anatolica, XIX, p.19-31.

Ehrich Robert W. (ed.)

1992 Chronologies in Old World Archaeology, Chicago and London.

\section{Esin Ufuk}

1993

Ein Beispiel für die kulturellen Beziehungen zwischen Zentral-anatolien und Südosteuropa während des Chalkolithikums, Anatolica, XIX, p.47-56. .

\section{Garasanin Draga}

1989 Starčevo und das makedonische Neolithikum, Macedoniae Acta Archaeologica, 10 (19851986), Skopje, p.37-45.

\section{Garałanin Draga și Milutin}

1961 L'habitat néolithique de Vršnik près de Tarinci, Zbornik na Štipskjot Naroden Muzej, II, p.7-40 si fig. 143.

\section{Garašanin M.}

1961 The Neolithic in Anatolia and the Balkans, Antiquity, 35, p. 272-278.

1971 Genetische und chronologische Problerre des frühkeramischen Neolithikums auf dem mittleren Balkan, in Actes du VIIF Congrès Intern. des Sciences Pré- et Protohistoriques, I, Beograd, p. 73-84.

1978 La néolithisation dans le sudest et dans le centre de la Peninsule Balkanique, Godišnjak-Sarajevo, XVI, p.31-44.

1979 Centralnobalkanska zona, in Praistorija Jugoslovenskich zemalja, II, Sarajevo, p.79-212.

\section{Georgiev Georgi I.}

1966 Über die Stratigraphie und Chronologie des Neolithikums, Äneolithikums und der Frühbronzezeit in Südbulgarien, in Actes du VII Congrès Intern. des Sciences Pré-et Protohistoriques, Prague, 21-27 août 1966, p.397-400.

1973 Die neolitische Kultur in Cavdar und ihre Stellung im Balkan-Neolithikum, in Actes du VII e Congrès Intern. des Sciences Pré- et Protohistoriques, II, Beograd, p. 263-273.

1975 Stratigraphie et caractère de la culture du site prehistorique du village Kremikovci, région de Sofia, Archeologija-Sofia, 17, p.17 şi urm. 
Nicolae URSULESCU

1981 Die neolitische Siedlung bei Coudar, Bez.Sofia, Izvestija Archeol. Inst., Sofia, 36, p. 63-109.

Gimbutas Marija

1972 Excavations at Anza, Macedonia, Archaeology, 25, 2, p. 112-123.

1974 Achilleion. A Neolithic mound in Thessaly, Journal of Field Archaeology, I, p. $277-302$.

Gimbutas M.(ed.)

$1976 \quad$ Neolithic Macedonia, I, Los Angeles.

\section{Grammenos Dimitros V.}

1993 Ansichten und Ergebnisse zu einigen wesentlichen Fragen der neolithischen Forschungen im Südbalkan, Anatolica, XIX, D. 57-62.

\section{Grbic Miodrag}

1960 Porodin, Bitolj.

\section{Hachmann Rolf}

1986 Fragen des frühen Neolithikums im östlichen Mittelmeerraum, BAM, XIII, 1986, p. 9-18. Jacobsen T.W.

1973 Excavations in the Franchti Cave, 1969-1971, Hesperia, 42, p. 45-88, 253-283.

\section{Jovanović Borislav}

1965 Genèse des types de céramique aux époques néolithique et énéolithique dans les Balkans et la région danubienne, Starinar, XIII-XIV (1962-1963), p.22-25.

1968 Historique de linndustrie céramique dans le néolithique et le haut énéolithique du Balkan central, in Les régions centrales des Balkans à l'epoque néolithique (ed. Lazar Trifunović), Beograd, p. XIII-XVIII.

\section{Kalicz Nándor}

1990 Frühneolithische Siedlungsfunde aus Südwestungarn, Budapest.

\section{Karmanski Sergej}

1968 Silkana keramika sa lokaliteta Donja Branjevina kod Deronja, Odžaci.

1975 Ornamentika na keramici sa lokaliteta Donja Branjevina kod Deranja, Odžaci.

1979 Donja Branjevina, Odžaci.

1988 Donja Branjevina 1986, Odžaci.

1991 Donja Branjevina, Odžaci.

\section{Korfmann Manfred}

1983 Demircihüyük. Architektur, Stratigraphie und Befunde,Mainz.

\section{Korošec Pia și Josip}

1973 Predistoriska naselba Barutnica kaj Amzibegovo, wo Makedonija, in Dissertations et Monographiae, XV, Prilep.

\section{Lazarovici Gheorghe}

1977 Die Beziehungen der Vinča A Phase zu Nordthessalien und dem Südbalkan, Apulum, XV, p. 19-26.

1979 Neoliticul Banatului, Cluj-Napoca. 
1983 Neoliticul timpuriu din zona Portilor de Fier (Clisură), Banatica, vII, p. 9-34.

1984 Neoliticul timpuriu'din Románia, AMPor, 8, p. 49-104.

1984a Die Vinča-Kultur und ihre Beziehungen zur Linearbandkeramik, NNU, 52 (1983), p. 131-176.

1985 Sincronisme etno-culturale in neoliticul timpuriu din Sălaj şi din vestul României, AMPor, 9, p. 69-93.

1995 Über das Frühneolithikum in Süd-Osten Europas (I. Rumänien), in Kulturraum mittlere und untere Donau: Traditionen und Perspektiven des Zusammenlebens, Resita, p. 33-35.

1996. The Process of Neolithisation and the development of the First Neolithic Civilisation in the Balkans, in XIII Int. Congress of Prehistoric and Protohistoric Sciences, Section 9, Colloquium XVII, Forli, p. 21-38.

\section{Lazarovici Gh., Maxim Zoia}

1995 Gura Baciului, Cluj-Napoca.

\section{Lazarovici Gh., Nica Marin}

1991 Chalcoliticul balcano-anatolian, in Cultura Vinča în România, Timişoara, p. 5-16.

Lichardus Jan

1972 Zur Entstehung der Linearbandkeramik, Germania, 50, p. 1-15.

Lichardus J. et al.

1985 La Protohistoire de l'Europe. Le Néolithique et le Chalcolithique, Paris.

\section{Lichardus-Itten Marie}

1993 Zum Beginn des Neolithikum im Thal der Struma, Anatolica, XIX, p. 99-116.

\section{Luca Sabin Adrian}

1991 Stratigraphie et chronologie. Le plus ancien rapport stratigraphique d'entre les cultures Starčevo-Cris et Vinča -corrélation d'entre les niveaux $V$ et $I V$ de Liubcova-Ornita, Banatica, 11, p. 141-155.

\section{Markevic Vsevolod I.}

1974 Bugo-dnestrovskaja kultura na territorii Moldavii, Chişinău.

\section{Meier-Arendt Walter}

1989 Überlegungen zur Herkunft des linienbandkeramischen Langhauses, in Neolithic of Southeastern Europe and its Near Eastern Connections, VAH, II, Budapest, p. 183-189.

Mellaart James

1960 Anatolia and the Balkans, Antiquity, 34, p. 270-278.

1970 Excavations at Hacilar, I-II, Edinburgh.

1975 The Neolithic of the Near East, London.

\section{Mikič Živko}

1990 Lepenski Vir und das Neolithisationsproblem in der Anthropologie, in Vinča and its World, Beograd, p. 61-65.

\section{Milojécić Vladimir}

1949 Chronologie der jüngeren Steinzeit Mittel-und Südosteuropas, Berlin. 
1950 Körös-Starčevo-Vinča, in Reinecke-festschrift, Mainz, p.108-118.

1960 Präkeramisches Neolithikum auf Balkanhalbinsel, Germania, 38, p. 320-335.

Minichreiter Kornelija

1992 Starčevacka kuttura u Severnoj Hrvatskoj, Zagreb.

\section{Necrasov Olga, Cristescu Maria}

1973 Structure anthropologique des tribus néo-énéolithiques et de l'Âge du Bronze de la Roumanie, in Fundamenta, Reihe B, Bd. 3 (Die Anfange des Neolithikums vom Orient bisNordeuropa), Teil VIIIa (Anthropologie), Köln, p. 137-152.

\section{Némejcová - Pavúková}

1993 Zum Charakter des Chalkolithikums im nordägäischen Raum, Anatolica, XIX, p. 243-249.

\section{Nica Marin}

1976 Circea, cea mai veche aşezare neolitică de la sud de Carpati, SCIVA, 27, 4, p. 435-463.

1977 Nouvelles donnés sur le Néolithique ancien d'Olténie, Dacia, NS, XXI, p. 13-53.

1991 Le groupe culture/ Circea-Grădinile dans le contexte du Néolithique balkanique, Zbornik Norodnog Muzeja, XIV, 1, Beograd, p. 103-112.

1995 Le groupe culture/ Circea-Grádinile dans le contexte du Nélithique balkanique et anatolien, AMNap, 32, 1, p. 11-28.

\section{Nikolov Bogdan}

1974 Gradechnitza, Sofía.

\section{Nikolov Vasil}

1984 Die Ornamenteverzierung der bemalten frühneolithischen Keramik aus der Ebene von Sofia, Studia Praehistorica, 7, p. 17-32.

1989 Das frühneolitihische Haus von Slatina, Germania, 67, 1, p. 149.

1995 Bemerkungen zur gemalten Ornamentierung auf den Tongefássen aus Caudar (Grupe Kremikovci), AMNap, 32, 1, p. 53-65.

Nikolov V., Grigorova K., Sirakova E.

1992 Die Ausgrabungen in der frühneolithischen Siedlung von Sofia-Slatina, Acta Praehistorica et Archaeologica, 24, p. 221-233.

\section{Özdołan Mehmet}

1983 Pendik: A Neolithic Site of Fikirtepe Culture in the Marmara Region, in Beiträge zu Altertumskunde Keinasiens. Festchrift für Kurt Bittel (eds. R.M. Boemer, H. Hauptmann), Mainz, p. 401-411.

1985 The Chalcolithic Pottery of Yarimburgaz Cave, in Studi di Paletnologia in onore di Salvatore M. Puglisi, Roma , p. 177-189.

1989 Neolithic Cultures of Northwestern Turkey. A general Appraisal of the Evidence and some Considerations, in Neolithic of Southeastern Europe and its Near Eastern Connections (ed. Sándor Bökönyi), VAH, II, Budapest, p. 201-215. Vinča and Anatolia: a new look at a very old problem, Anatolica, XIX, p.173-193. 


\section{Parzinger Hermann}

1993 Studien zur Chronologie und Kulturgeschichte der Jungstein-, Kupfer- und Frühbronzezeit zwischen Karpaten und Mittleren Taurus, Mainz am Rhein.

Parzinger H., Ozdoğan Mehmet

1995 Vortrag zur Jahressizzung 1995 der Römisch-Germanischen Kommission. Die Ausgrabungen in Kirklareli (Türkisch-Thrakien) und ihre Bedeutung für die Kulturbeziehungen zwischen Anatolien und dem Balkan vom Neolithikum bis zur Frühbronzezeit, BRGK, 76, p. 5-29.

\section{Passek Tatjana S., Cernyš Ekaterina K.}

1963 Pamjatniki ku/tury linejno-lentočnoj keramiki na territorii SSSR, in Archeologhija SSSR, v. B1-11, Moskva.

Paul Iuliu

1989 Unele probleme ale neoliticului timpuriu din zona carpato-dunăreană, SCIVA, 40, 1, p. 3-27.

1995 Aspekte des Karpatisch-Balkanisch-Donauländischen Neolithikums (Die Präcris-Kultur), in Vorgeshichtilche Untersuchungen in Siebenbürgen, Alba Iulia, p.28-68 + XXXIII pl.

\section{Pavúk Juraj}

1970 Die Zivilisation der Jungsteinzeit in der Slowakei, in Die Slowakei in der jüngeren Steinzeit, Bratislava, p. 245-262.

1980 Ätere Lineankeramik in der Slowakei, SlovArch, 28, p. 7-90.

1993 Beitrag zur Definition der Protostarčevo-Ku/tur, Anatolica, XIX, p. 231-242.

1994 Zur relativen Chronologie der ätteren Linearkeramik, Jósa András Múzeum Evkönyve, DOOVI, Nyiregyháza, p. 135-149.

1996 Frühneolithische Kulturen auf dem Zentralbalkan und der Beginn des Neolithikums in Mitteleuropa, in XIII Int.Congress of Prehistoric and Protohistoric Sciences, Section 9, Colloquium XVII, Forli, p. 39-44.

\section{Pavúk J., Bakamska Aneta}

1989 Beitrag der Ausgrabung in Galabnik zur Efforschung des Neolithikums in Südosteuropa, in Neolithic of Southeastem Earope and its Near Eastem Connections, VAH, II, p. 223-232.

\section{Pavúk J., Cochadžiev M.}

$1984 \quad$ Neolithische Tellsiedlung bei Galabnik in Westbulgarien, SlovArch, 32, p. 195-228.

\section{Perles Catherine}

1987 Les industries du Néolithique "précéramique" de Grèce: nouvelles études, nouvelles interprétations, in Chipped Stone Industries of Early Farming Cultures in Europe, Archaeologia Interregionalis, Warszawa, p.19-39.

\section{PerniCeva Liliana}

1990 Le site de Kovačevo, néolithique ancien, dans le département de Blagoevgrad, Studia Praehistorica, 10, p.142-196. 